\title{
Effect of ammonium chloride in plating baths on soft magnetic properties of electroplated Fe-Ni films
}

\author{
T. Yanai, K. Koda, K. Eguchi, K. Takashima, T. Morimura, M. Nakano, H. Fukunaga \\ Nagasaki University, 1-14 Bunkyo-Machi, Nagasaki 852-8521, Japan
}

\begin{abstract}
We electroplated $\mathrm{Fe}-\mathrm{Ni}$ films in plating baths with ammonium chloride $\left(\mathrm{NH}_{4} \mathrm{Cl}\right)$ and evaluated the magnetic properties of the films. The amount of $\mathrm{NH}_{4} \mathrm{Cl}$ did not affect the current efficiency of the plating process and the Fe content in the film. The obtained current efficiency of approximately $95 \%$ is much higher than our previous study. The coercivity dramatically decreased with increasing $\mathrm{NH}_{4} \mathrm{Cl}$ from 0 to $15 \mathrm{~g} / \mathrm{L}$, and we obtained $\mathrm{Fe}_{22} \mathrm{Ni}_{78}$ films with very low coercivity $(10 \mathrm{~A} / \mathrm{m})$. The $\mathrm{Cl}^{-}$concentration in the plating bath affected the coercivity, and we found that a plating bath with moderate low concentration of $\mathrm{Cl}^{-}$is preferred for obtaining the $\mathrm{Fe}_{22} \mathrm{Ni}_{78}$ films with low coercivity.
\end{abstract}

Index Terms — Soft magnetic material, Electroplating, Permalloy, Film

\section{INTRODUCTION}

$\mathrm{F}$ luxgate sensors are one of attractive current sensors since they have high sensitivity and enable us to detect both dc and ac current. Focusing on these advantages, we have prepared a fluxgate sensor using an electroplated Fe-Ni-Co thick-film $(\approx 20 \mu \mathrm{m})$ [1]. Owing to high economic viability of fabrication process, an electroplating is a hopeful method to obtain soft magnetic cores in fluxgate sensors, and some researchers also reported fluxgate sensors using electroplated soft magnetic alloys [2-3].

In general, $\mathrm{Fe}$ ions in a plating bath are not stable, and tend to be precipitated as hydroxide. Thus, a complexing agent is typically used for electroplating of Fe-group films. For the plating of Fe-group films, citrates are one of hopeful complexing agents [4-5], and chloride media are also often employed [6-7]. Osaka et al. have been reported Co-Fe-Ni films with high saturation magnetic flux density and low coercivity using ammonium chloride $\left(\mathrm{NH}_{4} \mathrm{Cl}\right)$ [8]. For electroplating of $\mathrm{Ni}$ films, the effect of $\mathrm{NH}_{4} \mathrm{Cl}$ on the crystal orientation has been reported [9]. As the orientation is one of factors to determine magnetic properties, we expected an improvement in soft magnetic properties of electroplated Fe$\mathrm{Ni}$ films. In the present study, we electroplated Fe-Ni films prepared in plating baths with $\mathrm{NH}_{4} \mathrm{Cl}$ and evaluated the magnetic properties of the films.

\section{EXPERIMENTAL PROCEDURES}

\section{A. Electroplating}

We carried out an electroplating to obtain Fe-Ni films by using a direct current. The composition of the plating bath and the plating conditions are shown in Tables 1 and 2, respectively.
Table 1 Plating bath conditions.

\begin{tabular}{cc}
\hline \hline Components & Concentration \\
\hline $\mathrm{NiSO}_{4} \cdot 6 \mathrm{H}_{2} \mathrm{O}$ (Nickel sulfate) & $275 \mathrm{~g} / \mathrm{L}$ \\
$\mathrm{FeSO}_{4} \cdot 7 \mathrm{H}_{2} \mathrm{O}$ (Iron sulfate) & $43-53 \mathrm{~g} / \mathrm{L}$ \\
$\mathrm{C}_{7} \mathrm{H}_{4} \mathrm{NNaO}_{3} \cdot 2 \mathrm{H}_{2} \mathrm{O}$ (Saccharin) & $10 \mathrm{~g} / \mathrm{L}$ \\
$\mathrm{NaCl}$ (Sodium chloride) & $0-50 \mathrm{~g} / \mathrm{L}$ \\
$\mathrm{NH}_{4} \mathrm{Cl}$ (Ammonium chloride) & $0-50 \mathrm{~g} / \mathrm{L}$ \\
\hline \hline
\end{tabular}

Table 2 Plating conditions.

\begin{tabular}{cc}
\hline \hline Conditions & Values \\
\hline Bath temperature & $50^{\circ} \mathrm{C}$ \\
$\mathrm{pH}$ & Approx. 3.4 \\
(Not adjusted) & $200 \mathrm{~mA} / \mathrm{cm}^{2}$ \\
Current density & $10 \mathrm{~min}$ \\
Plating time & $5 \mathrm{~mm} \times 15 \mathrm{~mm}$ \\
Anode $(\mathrm{Ni})$ & $5 \mathrm{~mm} \times 15 \mathrm{~mm}$ \\
Substrate $(\mathrm{Cu})$ &
\end{tabular}

\section{B. Measurements}

The dc-hysteresis loops were measured with a B-H tracer (Riken Denshi BHS-40), and we obtained the coercivity values from the measured loos. As we fixed the current density and the plating time, all films showed almost the same thickness (Approx. $20 \mu \mathrm{m}$ ). The compositions and crystal structures of the films were analyzed by EDX (Hitachi Hightechnologies S-3000) and XRD (Miniflex 600-DX), respectively. The thicknesses of the as-plated Fe-Ni films were measured with a micrometer (Mitutoyo, CPM15-25MJ). The current efficiency was calculated from the actual weight of electroplated Fe-Ni films and the theoretical weight obtained by the Faraday's law. All measurements were carried out for the Fe-Ni films in an as-plated state. 


\section{RESULTS AND DISCUSSION}

Figure 1 shows Fe content and current efficiency as a function of $\mathrm{NH}_{4} \mathrm{Cl}$ concentration. The concentrations of $\mathrm{FeSO}_{4}$ and $\mathrm{NaCl}$ were fixed at 53 and $50 \mathrm{~g} / \mathrm{L}$, respectively. In our previous study for the citric acid, both the current efficiency and the Fe content decreases with increasing the concentration of the citric acid [5]. In contrast, both the current efficiency and the Fe content show almost constant values except for 0 $\mathrm{g} / \mathrm{L}$ of $\mathrm{NH}_{4} \mathrm{Cl}$, indicating that we can vary the concentration of $\mathrm{NH}_{4} \mathrm{Cl}$ without the change in the $\mathrm{Fe}$ content. The current efficiency of approximately $95 \%$ is much higher than those for our previous study (85\%) [5] and other researcher's ones (60 $80 \%$ ) [10-11].

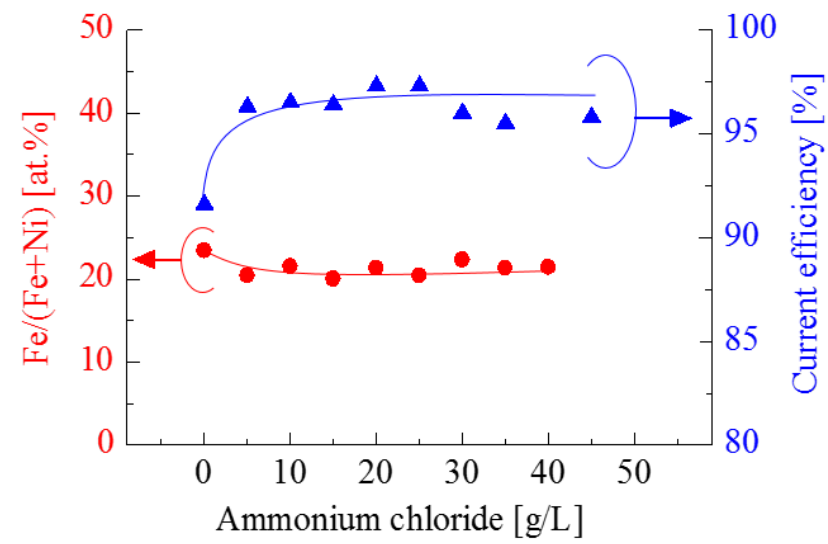

Fig. $1 \mathrm{Fe}$ content and current efficiency as a function of $\mathrm{NH}_{4} \mathrm{Cl}$ concentration. The concentrations of $\mathrm{FeSO}_{4}$ and $\mathrm{NaCl}$ were fixed at 53 and $50 \mathrm{~g} / \mathrm{L}$, respectively.

Figure 2 shows coercivity of the $\mathrm{Fe}_{22} \mathrm{Ni}_{78}$ films as a function of $\mathrm{NH}_{4} \mathrm{Cl}$ concentration. The results for the plating baths with 15 and $50 \mathrm{~g} / \mathrm{L}$ of $\mathrm{NaCl}$ are shown in Fig.2. The insets indicate photographs and SEM images of the films for 0 and $15 \mathrm{~g} / \mathrm{L}$ of $\mathrm{NH}_{4} \mathrm{Cl}$. The coercivity dramatically decreases with increase the $\mathrm{NH}_{4} \mathrm{Cl}$ followed by a slight increase in higher $\mathrm{NH}_{4} \mathrm{Cl}$ concentration region. Since addition of the $\mathrm{NH}_{4} \mathrm{Cl}$ improves the surface condition as shown in the insets, we considered that the dramatic decrease in the coercivity is attributed to the improvement in the surface quality of the films. In our experimental conditions, the coercivity value for $\mathrm{NaCl}=15$ $\mathrm{g} / \mathrm{L}$ shows much smaller than those for $\mathrm{NaCl}=50 \mathrm{~g} / \mathrm{L}$ and our previous study (broken line in Fig.2) [5].

As mentioned-above, we observed the slight increase of coercivity in higher $\mathrm{NH}_{4} \mathrm{Cl}$ concentration region. Figure 3 shows the coercivity of the $\mathrm{Fe}_{22} \mathrm{Ni}_{78}$ films as a function of the $\mathrm{Cl}^{-}$concentration in the plating baths. The $\mathrm{Cl}^{-}$concentration was calculated using concentrations of $\mathrm{NH}_{4} \mathrm{Cl}$ and $\mathrm{NaCl}$ in the bath. Since the surfaces of the films were very rough in low $\mathrm{Cl}^{-}$concentration region $(<0.5 \mathrm{~mol} / \mathrm{L})$, we only show the results for the $\mathrm{Fe}_{22} \mathrm{Ni}_{78}$ films with smooth surfaces in Fig.3 in order to remove the effect of surface roughness on coercivity.
The coercivity increases with increasing the $\mathrm{Cl}^{-}$concentration. From these results, we found that a plating bath with moderate low concentration of $\mathrm{Cl}^{-}$is preferred for obtaining the $\mathrm{Fe}_{22} \mathrm{Ni}_{78}$ films with good soft magnetic properties.

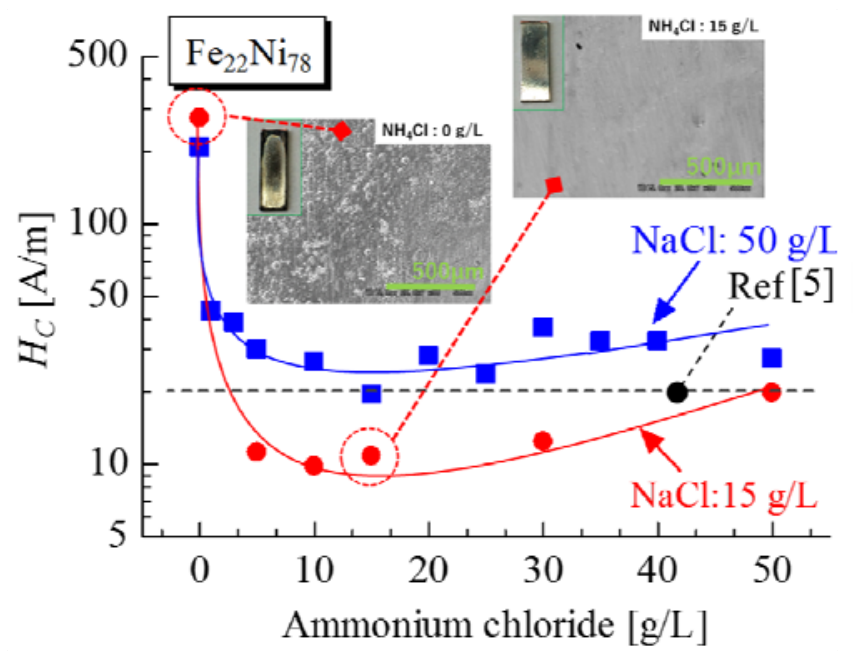

Fig. 2 Coercivity as a function of $\mathrm{NH}_{4} \mathrm{Cl}$ concentration. The insets indicate photographs and SEM images for the $\mathrm{Fe}_{22} \mathrm{Ni}_{78}$ films for 0 and $15 \mathrm{~g} / \mathrm{L}$ of $\mathrm{NH}_{4} \mathrm{Cl}$.

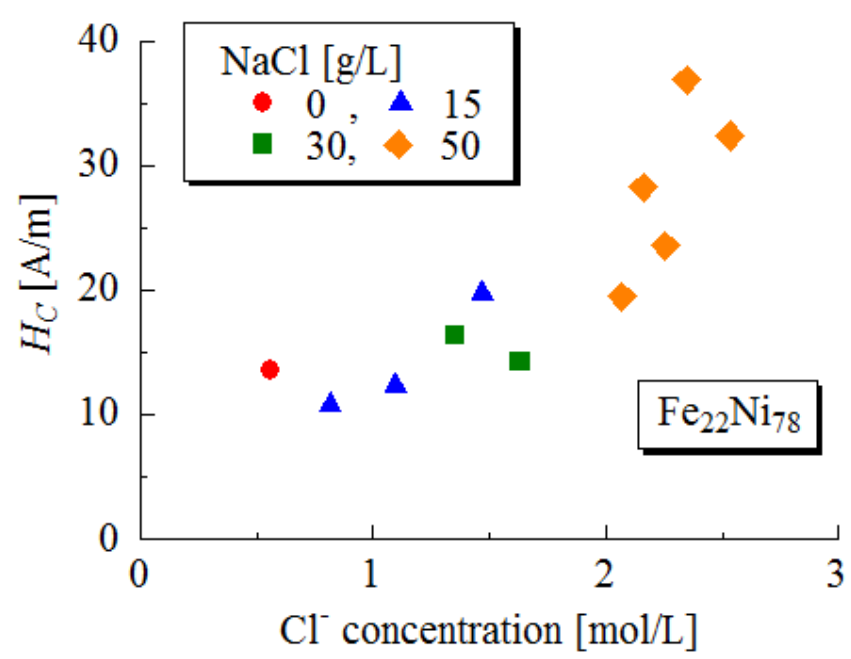

Fig.3. Coercivity of $\mathrm{Fe}_{22} \mathrm{Ni}_{78}$ films as a function of the $\mathrm{Cl}^{-}$ concentration in the plating baths.

In order to understand the change in the coercivity values shown in Fig.3, we carried out an XRD analysis. Figure 4 shows XRD patterns of $\mathrm{Fe}_{22} \mathrm{Ni}_{78}$ films prepared in the plating bath with various $\mathrm{Cl}^{-}$concentrations. The $\mathrm{Cl}^{-}$concentration was varied from 0.8 to $2.7 \mathrm{~mol} / \mathrm{L}$ by the change in the concentrations of $\mathrm{NaCl}$ and $\mathrm{NH}_{4} \mathrm{Cl}$. We also show the result for the citric-acid-based bath [12] in Fig.4. Fe-Ni grains in the films for the $\mathrm{NH}_{4} \mathrm{Cl}$ baths are oriented preferentially to the (111) plane compared with that for the citric acid bath, and this result agrees with that for Ni films [9]. Since the orientation slightly changes (111) to random with increasing the $\mathrm{Cl}^{-}$concentration, we considered that slight increase in the coercivity in higher $\mathrm{Cl}^{-}$concentration is attributed to the 
changes in the grain orientation.

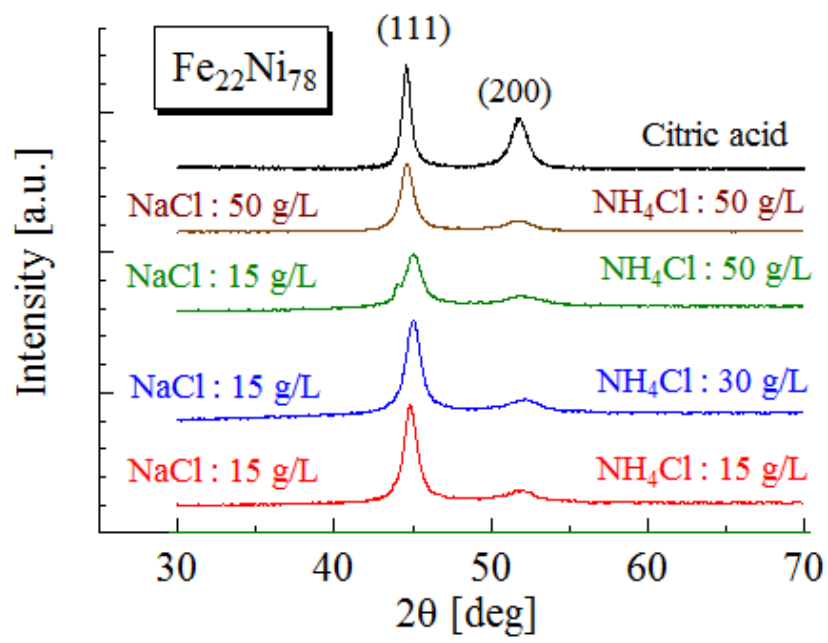

Fig.4 XRD patterns of $\mathrm{Fe}_{22} \mathrm{Ni}_{78}$ films prepared in the plating bath with various $\mathrm{Cl}^{-}$concentrations. The $\mathrm{Cl}^{-}$concentration was varied from 0.8 to $2.7 \mathrm{~mol} / \mathrm{L}$ by the change in the concentrations of $\mathrm{NaCl}$ and $\mathrm{NH}_{4} \mathrm{Cl}$.

\section{CONCLUSIONS}

In conclusion, we have investigated the effect of ammonium chloride in plating baths on soft magnetic properties of electroplated $\mathrm{Fe}-\mathrm{Ni}$ films. The obtained results are summarized as follows:

(1) The plating process using ammonium chloride showed high current efficiency ( $>95 \%$ ), and $\mathrm{NH}_{4} \mathrm{Cl}$ concentration did not affect Fe content of the films.

(2) Fe-Ni grains in the films for the $\mathrm{NH}_{4} \mathrm{Cl}$ baths are oriented preferentially to the (111) plane.

(3) Plating baths with moderate low $\mathrm{Cl}^{-}$concentration is preferred for obtaining the $\mathrm{Fe}_{22} \mathrm{Ni}_{78}$ films with good soft magnetic properties.

\section{ACKNOWLEDGMENT}

Part of this work was carried out under the Cooperative Research Project Program of the Research Institute of Electrical Communication, Tohoku University.

\section{REFERENCES}

[1] Y. Watanabe, M. Otsubo, A. Takahashi, T. Yanai, M. Nakano, and H. Fukunaga, "Temperature Characteristics of a Fluxgate Current Sensor with Fe-Ni-Co Ring Core," IEEE Trans. Magn., 51, No.11, (2015), \#4004104.

[2] Hae-Seok Park, Jun-Sik Hwang, Won-Youl Choi, Dong-Sik Shima, Kyoung-Won Na, Sang-On Choi, "Development of micro-fluxgate sensors with electroplated magnetic cores for electronic compass," Sens. Act., A 114, (2004), pp. 224-229.
[3] Trifon M. Liakopoulos, Chong H. Ahn, "A micro-fluxgate magnetic sensor using micromachined planar solenoid coils," Sens. Act., 77, (1999), pp. 66-72.

[4] Y. Zhang and D. G. Ivey, "Electroplating of Nanocrystalline CoFeNi Soft Magnetic Thin Films from a Stable Citrate-Based Bath," CHEMISTRY OF MATERIALS, 16, (2004), pp. 1189-1194.

[5] Y. Watanabe, T. Yanai, M. Otsubo, A. Takahashi, T. Ohgai, M. Nakano, K. Suzuki, and H. Fukunaga, "Improvement in current efficiency of electroplated Fe-Ni films prepared in citric-acid-based baths," J. Appl. Phys, 117, (2015), \#17A32.

[6] N.V. Myung, D.Y. Park, D.E. Urgiles, T. George, "Electroformed iron and FeCo alloy," Electrochimica Acta, 49, (2004), pp. 4397-4404

[7] Tabakovic, J. Gong, S. Riemer, V. Venkatasamy, M. Kief, "Stress evolution in $\mathrm{Co}_{\mathrm{x}} \mathrm{Fe}_{1-\mathrm{x}}(\mathrm{x}=0.33-0.87)$ electrodeposited films," Electrochimica Acta, 55, (2010), pp. 9035-9041.

[8] T. Osaka, M. Takai, K. Hayashi, K. Ohashi, M. Saito, K. Yamada, "A soft magnetic CoNiFe film with high saturation magnetic flux density and low coercivity," Nature, 392, (1998), pp.796-798.

[9] M. Hashemzadeh, K. Raeissi, F. Ashrafizadeh, S. Khorsand, "Effect of ammonium chloride on microstructure, super-hydrophobicity and corrosion resistance of nickel coatings," Surface \& coating Technology, 283, (2015), pp. 318-328.

[10] J.-M. Quemper, S. Nicolas, J. P. Gilles, J. P. Grandchamp, A. Bosseboeuf, T. Bourouina, and E. Dufour-Gergam, "Permalloy electroplating through photoresist molds," Sens. Act., 74, (1999), pp. 1-4.

[11] E. R. Spada, L.S. de Oliveira, A. S. da Rocha, A. A. Pasa, G. Zangari, and M. L. Sartorelli, "Thin films of $\mathrm{Fe}_{x} \mathrm{Ni}_{1-\mathrm{x}}$ electroplated on silicon (100),” J. Magn. Magn. Mater., 272-276, (2004), E891-E892.

[12] T. Shimokawa, T. Yanai, K. Takahashi, M. Nakano, K. Suzuki, and H. Fukunaga, "Soft Magnetic Properties of Electrodeposited Fe-Ni Films Prepared in Citric Acid Based Bath," IEEE Trans. Magn., 48, (2012), pp. 2907-2909. 